DOI: https://doi.org/10.30525/2661-5150/2021-3-6

\title{
STATE AND PROSPECTS OF THE DERIVATIVES WORLD MARKET DEVELOPMENT
}

\author{
Marharyta Krasnova ${ }^{1}$
}

\begin{abstract}
The purpose of the paper is to determine the current state of the global derivatives market in the context of structural and dynamic processes and to substantiate the prospects for its further development, given the existing global challenges. Methodology. The research is based on analysis and comparison of data from the Bank for International Settlements (BIS) for the period from 2000 to 2020. The paper uses methods of correlation analysis to establish the relationship between the state of the world economy and the size of the derivatives market. The method retrospective study of the dynamic series was applied to structure information of derivatives world market development. To reveal the features, the specifics of the usage of various mechanisms and tools for the distribution of derivatives, and established the differences between exchange and over-the-counter trading article applies elements of structural analysis. The results of the study showed the importance and scale of the global derivatives market for the global economy. They allowed us to reveal a close relationship between market size and world GDP and assess the structural features of the market. Accordingly, the derivatives market development has been periodized since 2000. Its structural features have been revealed in terms of the type of transactions, underlying asset, place, and currency of derivatives trading, their maturity, etc. Consequently, a significant predominance of OTC derivatives trading has been found, due to greater flexibility of instruments and less formalized control. The predominance of different types of derivative instruments in different segments of the market has been determined. Practical implications. The obtained conclusions are of interest in terms of monitoring the world derivatives market. They allow the correct assessment of the processes occurring in the market and respond to them rationally. The scientific confirmation of the connection between the size of the world economy and the market for derivative financial instruments is of particular practical importance. Systematization of market reform directions allows a better understanding of the ongoing processes in the over-the-counter derivatives market. Value/originality. The value of the article lies in the complexity of the analysis of the state and prospects of the derivatives world market development. It is provided through a detailed structural analysis, extrapolated to measures of market system transformation, as well as possible prospects for its further development.
\end{abstract}

Key words: derivative, exchange, futures, options, forwards, swaps, clearing, over the counter.

JEL Classification: G15, G23

\section{Introduction}

In the 21 st century, globalization and digitalization have deeply permeated all aspects of human life. They have covered almost every country in the world, providing access to the benefits of modern civilization, including effective economic instruments. Among the existing global institutions, a special place is occupied by the global financial market and its components: money and currency markets, credit market, securities, and financial services markets, the market of derivative financial instruments (derivatives).

Derivative instruments hold a special place in the structure of the world financial system. First of all, their derivative nature and connection to various underlying

Corresponding author:

${ }^{1}$ Kyiv National Economic University named after Vadym Getman, Ukraine.

E-mail: kmargobl@gmail.com

ORCID: https://orcid.org/0000-0001-6315-3168 assets (goods and raw materials, securities, interest and credit rates, exchange rates, stock indices, statistical reporting data, environmental indicators, etc.) allow the unification of the world financial market into a single harmonious system. In addition, the purpose and functional features of derivatives create favourable conditions for their widespread use as an effective tool for hedging risks, improving the liquidity of assets and increasing their value, forecasting economic and financial indicators.

Today, the global derivatives market is the subject of profound research and monitoring among scientists (Afrina, Beg, Zayed, Hossain, Shahi, 2020; Sheludko, 2014; Vo D., Huynh S., Vo A., Ha D., 2019),

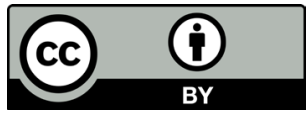

This is an Open Access article, distributed under the terms of the Creative Commons Attribution CC BY 4.0 
experts (Bank for International Settlements (BIS), 2019; Greenberger, 2010; The Financial Crisis...), government and international officials (The World Bank, 2021). Despite the significant positive effect, its instruments also include considerable speculative risks. It is considered that the global financial crisis of 2008, the numerous shocks to the financial sector, and the bankruptcy of leading financial institutions are all connected to these risks.

Due to the current importance and scale of the global derivatives market, significant scientific tasks occurred including the need for continuous monitoring of its condition, identification, and analysis of key indicators, as well as substantiation of further prospects of operation, based on existing trends and global processes.

Accordingly, the purpose of our study is to determine the current state of the global derivatives market in the context of structural and dynamic processes and to substantiate the prospects for its further development, given the existing global challenges. The objectives of the study are subordinated to achieving the purpose and focused on the following aspects: determining the importance of derivatives in the world economy; analysis of the current state of the world derivatives market and identification of its structural features; coverage of the processes related to the reform of the global derivatives market; substantiation of prospects for its further development.

The methodological basis of the study is the analysis of the most relevant and large-scale summary data from the Bank for International Settlements (BIS) (Bank for International Settlements (BIS), 2019), which covers derivatives traded on organized exchanges, outstanding positions in over-the-counter (OTC) derivatives markets, and turnover in foreign exchange and OTC interest rate derivatives markets.

Comparison of the mentioned data with world economy state indicators carried out based on correlation analysis allowed to establish the relationship between global GDP and the size of the derivatives market.

A retrospective study of the dynamic series of the derivatives market made it possible to structure information on the stages of its development. Structural analysis of the derivatives market revealed the geographical features, the specifics of the usage of various mechanisms and tools for the distribution of derivatives, and established the differences between exchange and over-the-counter trading. Based on the processing of monitoring data by The Financial Stability Board (FSB) (The Financial Crisis...), the main areas of reforming the system of derivative financial instruments were systematized and generalized, the impact of the applied transformations on the market situation was determined. Based on the results of the study, by extrapolating them to the current situation in the financial market, the prospects for further development of the derivatives market were substantiated. Based on the result of the study, extrapolating them to the current situation in the financial market were substantiated the prospects for further development of the derivatives market.

\section{The meaning of derivatives in the world economy}

The global derivatives market has undergone tremendous change over the past two decades and, by most measures, has come out more robust and efficient than ever. Its main features are increased transparency, more central clearing, and vastly improved technology for trading, clearing, and risk - managing everything from futures to swaps to options (McPartland, Manohan, 2020).

Since the end of 2000, the derivatives market has received a push to development due to the signing of The Commodity Futures Modernization Act of 2000 (CFMA), which minimized the ability to control the derivatives market. Such actions, on the one hand, provided a six-fold increase increase in the volume of transactions with derivative financial instruments in just seven years (from $\$ 107.9$ trln to $\$ 657.5$ trln), and on the other hand, led to market imbalance and, according to M. Greenberger (Greenberger, 2010), became one of the causes of the global financial crisis of 2008. Following the situation, measures had been taken to control the market. That led to a slowdown in growth, and after 2013 - a reduction in transactions on the derivatives market. As a result, the total volume of the studied market in 2020 was $\$ 648.0 \operatorname{trln}$ (Figure 1).

In the context of retrospective analysis, we will highlight the existence of distinct periodization of the market development for derivative financial instruments within the study period:

2000-2007 - rapid growth and formation of preconditions for the global financial crisis;

2008-2013 - slowing down the market growth rate, implementation of strict market control measures;

2014-2020 - market downturn and stabilization, application of systemic reforms to control market functioning.

Evaluating the importance of derivatives for the world economy, we note that the total size of the derivatives market in some periods (2007-2010) exceeded world GDP by more than 10 times. Evaluating the importance of derivatives for the world economy, we note that the total size of the derivatives market in some periods (2007-2010) exceeded world GDP by more than 10 times. As of 2020, this advantage was 7.6 times. Thus, the high liquidity of derivatives as financial instruments can be considered one of the factors in the development of the world economy. We used correlation analysis in order to 


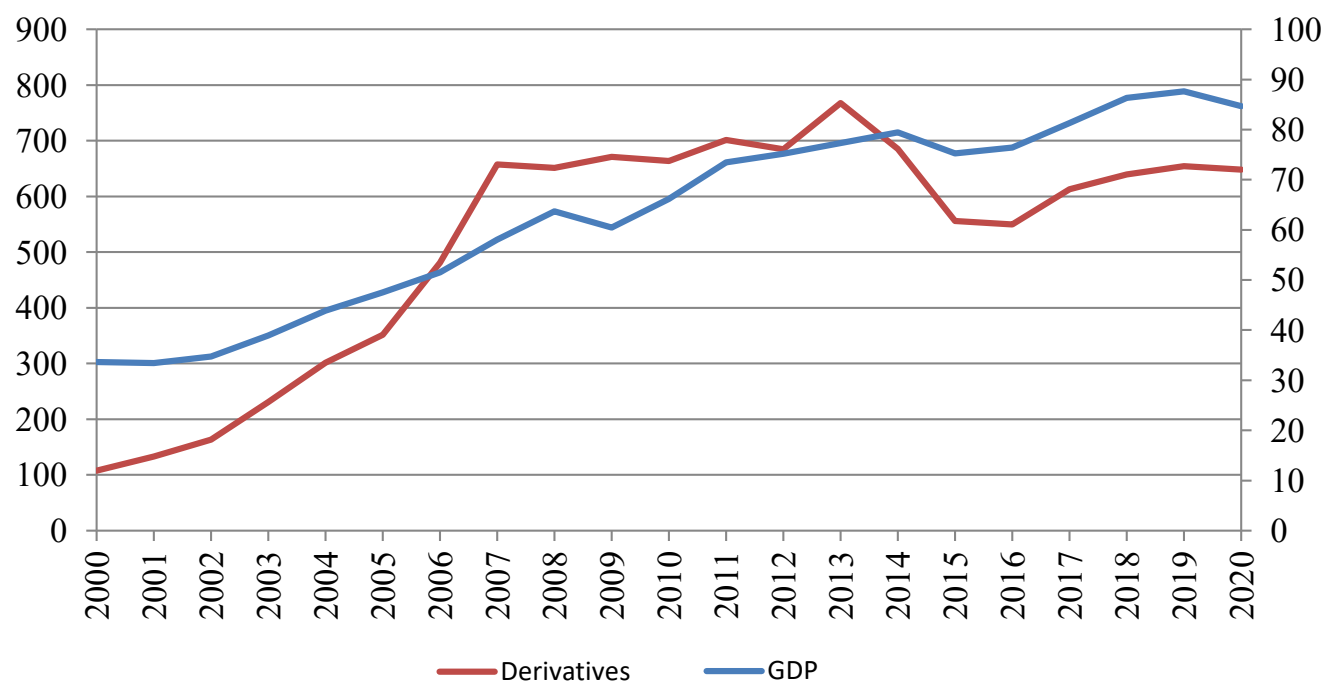

Figure 1. Comparison of the dynamic of the world GDP size and the world derivatives market in 2000-2020, $\$$ trln

Source: BIS (http://stats.bis.org)

test this assumption. The analysis also examined the correlation between the size of the world GDP $\left(\mathrm{x}_{2}\right)$, the derivatives market $\left(\mathrm{x}_{3}\right)$ with the time factor $\left(\mathrm{x}_{1}\right)$, as well as the correlation between the components of the derivatives market (exchange-traded $-\mathrm{x}_{4}$ and $\mathrm{OTC}-\mathrm{x}_{5}$ ) with these factors. The results of the analysis are presented in Table 1.

According to the results, it was found that all mentioned factors are characterized by a high degree of cross-correlation $\left(\mathrm{r}_{x \mathrm{x}}>0.7\right)$. In addition, the closest linear correlation with the time factor is characterized by the value GDP $\left(\mathrm{rx}_{1} \mathrm{x}_{2}=0.974\right)$ and exchange-traded derivatives $\left(\mathrm{rx}_{1} \mathrm{X}_{4}=0.828\right)$. The mutual linear correlation between GDP and the size of the derivatives market is $\mathrm{rx}_{2} \mathrm{x}_{3}=0.875$. The size of the derivatives market itself depends almost entirely on the OTC segment $\left(\mathrm{rx}_{3} \mathrm{X}_{5}=0.998\right)$.

Thus, the dynamics of the global derivatives market are closely correlated with the volume of global GDP. This allows economic agents to use derivatives effectively in the interests of business related to risk hedging, the value of assets, their liquidity increase, and allows the financial institutions to predict the dynamics of prices for underlying assets and more effectively manage financial resources.

\section{The current state of the world derivatives market}

As already stated, the global derivatives market has a complex structure. Depending on the place of transactions conclusion, it operates both Exchangetraded and over counter (OTC) derivatives. Depending on the type of transaction, it uses futures, options, forwards, and swaps. The first two types of transactions are standardized instruments and are traded on the exchange, while forward and swap contracts are more often objects of OTC trading. Depending on the underlying asset, derivatives are divided into the Interest rate, equity-linked, foreign exchange, commodity, credit derivatives, and others. At the same time, there are differences both between the instruments themselves and the underlying assets of exchange and over-the-counter derivatives.

Yes, for example, exchange-traded Interest rate derivatives are LTIR (long-term interest rate) and STIR (short-term interest rate) options and futures,

Table 1

Results of correlation analysis of the global GDP time trend and the world derivatives market

\begin{tabular}{|c|c|c|c|c|c|c|}
\hline \multicolumn{2}{|l|}{ Indicators } & Years & GDP & Derivatives & $\begin{array}{c}\text { Exchange-traded } \\
\text { derivatives }\end{array}$ & OTC derivatives \\
\hline Years & $\mathrm{x}_{1}$ & 1.000 & & & & \\
\hline GDP & $\mathrm{x}_{2}$ & 0.974 & 1.000 & & & \\
\hline Derivatives & $\mathrm{x}_{3}$ & 0.774 & 0.875 & 1.000 & & \\
\hline Exchange-traded derivatives & $\mathrm{x}_{4}$ & 0.828 & 0.825 & 0.767 & 1.000 & \\
\hline OTC derivatives & $x_{5}$ & 0.746 & 0.856 & 0.998 & 0.720 & 1.000 \\
\hline
\end{tabular}

Source: BIS (http://stats.bis.org); Worldbank (https://databank.worldbank.org/source/world-development-indicators) 
OTC Interest rate derivatives are called Forward rate agreements (FRA), interest rate swap (IRS), options CAP, FLOOR, COLLAR, and others. Exchange instruments related to shares are stock options and futures, stock indices, or shares of exchange-traded funds (ETFs). Relevant instruments on the OTC market are forwards, options, and swaps (Sheludko, 2014).

During the analysis of these derivative instruments, most of them can be divided by currency, location or counterparty, sometimes - by maturity, instrument and commodity, rating category.

The key parameters of the size and structure of the world market of derivative financial instruments are given in Table 2.

The derivatives market overall was demonstrating growing dynamics during 2015-2020. To the greatest extent, this is typical for the OTC market, which has continued to grow even during the crisis of 2020. In contrast, the exchange-traded derivatives segment last year fell by almost $\$ 30 \operatorname{trln}(-31.2 \%)$.

The leading role in the market structure is played by the OTC segment, which share ranges from 85 90\%. Constant growth of the Exchange-traded derivatives segment role was a distinctive trend of the last six-year period (increase in share from $11.4 \%$ to $14.6 \%$ in 2019). Under these circumstances, the COVID-2019 pandemic proved to be a deterrent to organized exchange trading in derivative financial instruments. In contrast, these events were not reflected in the OTC sector. It was the over-thecounter derivatives market that, due to its flexibility, hedged the risks of economic agents related to COVID-2019 and showed an increase of \$ $23.5 \mathrm{trln}$ $(+4.2 \%)$.
Assessing the role of exchange institutions for the derivatives market, we determine that by 2020 , more than $70 \%$ of derivative transactions took place in the markets of North America. Last year, this market was negatively affected by the pandemic and lockdown of the economy in most countries. As a result, the positions of European stock exchanges strengthened significantly (30.6\% instead of $22.9 \%$ in 2019 ), while the share of American exchanges decreased to $64.5 \%$. The total share of Asian, Pacific, and other exchanges during this period ranged from 3.2 to $5 \%$. In terms of the currency of exchange transactions with the Interest rate derivatives, the largest share in 2020 was occupied by the US Dollar (63.3\%), Pound Sterling (15.9\%), and EUR (14.5\%). In terms of the currency of derivative transactions, US Dollar was one of the currencies in $96.9 \%$, EUR - in $33.9 \%$, Brazilian Real - in $29.7 \%$ of cases (given that there are two currencies in exchange transactions, the total share of all currencies is $200 \%$ ).

Thus, the current state of the global derivatives market development is characterized by restrained positive dynamics, which to some extent (depending on the region or derivative instrument) has been adjusted due to the pandemic of COVID-2019 (Afrina, Beg, Zayed, Hossain, Shahi, 2020). OTC derivative transactions, for which the impact of the pandemic was insignificant, play a leading role in the market. Instead, the lockdown had a negative impact on the exchangetraded derivatives market. The greatest negative impact was recorded on the exchanges of North America, while in Europe it was less noticeable. As for the OTC derivatives market segment, it continued to grow despite the new circumstances. Moreover, it hedged

Table 2

The size and structure of the world derivatives market, $\$$ trln

\begin{tabular}{|l|c|c|c|c|c|c|c|c|c|c|c|c|}
\hline \multirow{2}{*}{ Market, tools } & \multicolumn{2}{|c|}{2015} & \multicolumn{2}{c|}{2016} & \multicolumn{2}{c|}{2017} & \multicolumn{2}{c|}{2018} & \multicolumn{2}{c|}{2019} & \multicolumn{2}{c|}{2020} \\
\cline { 2 - 13 } & $\$ \operatorname{trln}$ & $\%$ & $\$$ trln & $\%$ & $\$$ trln & $\%$ & $\$$ trln & $\%$ & $\$ \operatorname{trln}$ & $\%$ & $\$ \operatorname{trln}$ & $\%$ \\
\hline Exchange-traded derivatives & $\mathbf{6 3 . 5}$ & $\mathbf{1 1 . 4}$ & $\mathbf{6 7 . 2}$ & $\mathbf{1 2 . 2}$ & $\mathbf{8 1 . 0}$ & $\mathbf{1 3 . 2}$ & $\mathbf{9 4 . 8}$ & $\mathbf{1 4 . 8}$ & $\mathbf{9 5 . 8}$ & $\mathbf{1 4 . 6}$ & $\mathbf{6 5 . 9}$ & $\mathbf{1 0 . 2}$ \\
\hline Interest rate & 63.1 & 11.4 & 66.9 & 12.2 & 80.6 & 13.1 & 94.5 & 14.8 & 95.4 & 14.6 & 65.5 & 10.1 \\
\hline Foreign exchange & 0.4 & 0.1 & 0.3 & 0.1 & 0.4 & 0.1 & 0.4 & 0.1 & 0.4 & 0.1 & 0.5 & 0.1 \\
\hline OTC derivatives & $\mathbf{4 9 2 . 5}$ & $\mathbf{8 8 . 6}$ & $\mathbf{4 8 2 . 4}$ & $\mathbf{8 7 . 8}$ & $\mathbf{5 3 1 . 9}$ & $\mathbf{8 6 . 8}$ & $\mathbf{5 4 4 . 4}$ & $\mathbf{8 5 . 2}$ & $\mathbf{5 5 8 . 5}$ & $\mathbf{8 5 . 4}$ & $\mathbf{5 8 2 . 1}$ & $\mathbf{8 9 . 8}$ \\
\hline Interest rate contracts & 395.1 & 71.1 & 385.5 & 70.1 & 426.6 & 69.6 & 436.8 & 68.3 & 449.0 & 68.6 & 466.5 & 72.0 \\
\hline Foreign exchange contracts & 76.0 & 13.7 & 78.8 & 14.3 & 87.1 & 14.2 & 90.7 & 14.2 & 92.2 & 14.1 & 97.6 & 15.1 \\
\hline Credit derivatives & 12.6 & 2.3 & 10.1 & 1.8 & 9.6 & 1.6 & 8.4 & 1.3 & 8.1 & 1.2 & 8.6 & 1.3 \\
\hline Equity-linked contracts & 7.2 & 1.3 & 6.3 & 1.1 & 6.6 & 1.1 & 6.4 & 1.0 & 6.9 & 1.1 & 7.1 & 1.1 \\
\hline Commodity contracts & 1.5 & 0.3 & 1.7 & 0.3 & 1.9 & 0.3 & 1.9 & 0.3 & 2.1 & 0.3 & 2.1 & 0.3 \\
\hline Other derivatives & 0.1 & 0.0 & 0.1 & 0.0 & 0.1 & 0.0 & 0.2 & 0.0 & 0.2 & 0.0 & 0.2 & 0.0 \\
\hline In total, including by types of derivatives & $\mathbf{5 5 6 . 0}$ & $\mathbf{1 0 0}$ & $\mathbf{5 4 9 . 7}$ & $\mathbf{1 0 0}$ & $\mathbf{6 1 2 . 9}$ & $\mathbf{1 0 0}$ & $\mathbf{6 3 9 . 2}$ & $\mathbf{1 0 0}$ & $\mathbf{6 5 4 . 3}$ & $\mathbf{1 0 0}$ & $\mathbf{6 4 8 . 0}$ & $\mathbf{1 0 0}$ \\
\hline Interest rate & 458.3 & 82.4 & 452.4 & 82.3 & 507.2 & 82.8 & 531.3 & 83.1 & 544.4 & 83.2 & 532.0 & 82.1 \\
\hline Foreign exchange & 76.3 & 13.7 & 79.1 & 14.4 & 87.5 & 14.3 & 91.1 & 14.2 & 92.6 & 14.1 & 98.0 & 15.1 \\
\hline Credit derivatives & 12.6 & 2.3 & 10.1 & 1.8 & 9.6 & 1.6 & 8.4 & 1.3 & 8.1 & 1.2 & 8.6 & 1.3 \\
\hline Equity-linked contracts & 7.2 & 1.3 & 6.3 & 1.1 & 6.6 & 1.1 & 6.4 & 1.0 & 6.9 & 1.1 & 7.1 & 1.1 \\
\hline Commodity contracts & 1.5 & 0.3 & 1.7 & 0.3 & 1.9 & 0.3 & 1.9 & 0.3 & 2.1 & 0.3 & 2.1 & 0.3 \\
\hline Other derivatives & 0.1 & 0.0 & 0.1 & 0.0 & 0.1 & 0.0 & 0.2 & 0.0 & 0.2 & 0.0 & 0.2 & 0.0 \\
\hline
\end{tabular}

Source: BIS (http://stats.bis.org) 
some of the risks, the number and volume of which increased significantly in a pandemic.

\section{The structure of the world derivatives market}

Based on data published by the BIS (Bank for International Settlements (BIS), 2019), more than $82 \%$ of the derivatives market is provided by Interest rate contracts. Of this $-72 \%$ due to the OTC segment and only $10 \%$ - due to exchanges. Within OTC derivatives, Swaps take the lead (76.3\%). The share of FRAs is $15.6 \%$, Options are $8.0 \%$. Herewith, the main contractors are the central counterparty (CCP) (77.7 \%), mainly clearing house, an entity that helps facilitate trading in various derivatives and equities markets. The share of non-financial customers is only $2.7 \%$.

Foreign exchange derivatives are also important in the market. If within exchange trading their volume is only $\$ 0.5 \operatorname{trln}(0.1 \%$ of the total volume), then in the OTC segment it is $\$ 97.6 \operatorname{trln}(15.1 \%$ of the total volume). Within the exchanged market, future contracts predominate (\$326 trln - 72.4\%). Options account for $\$ 37.0 \operatorname{trln}(27.6 \%)$. At the same time, most agreements (over 90\%) are concluded on a shortterm basis and provide for quick liquidation.

The outright forwards and forex swaps (59.5\%) and Currency swaps $(28.5 \%)$ are the main derivative financial instruments in the OTC market. The share of options is $12.0 \%$. By counterparty, the reporting dealers (38.0\%) and other financial institutions (49.1\%) take an important place. However, unlike Interest rate contracts, the share of CCPs in circulation is only 3.9\%. By maturity, in the analysed segment preferences are given to short-term (up to 1 year) instruments (77.9\%), by currency, the share of the US dollar reaches $87.5 \%$.

In the commodity contracts market, the main underlying asset is gold (46.7\%), and other derivative instruments (54.7\%), including energy resources, agricultural products, and other commodities. The leading type of transaction in this market is Forwards and swaps (70.8\%). In the structure of credit derivatives, the vast share of transactions is covered by credit default swaps (96.6\%). The main counterparties are central counterparties $(60.4 \%)$, the share of nonfinancial customers is quite low $-3.5 \%$.

The equity-linked contracts market is distinguished by the parity of the instruments used (51.4\% forwards and swaps, and $48.6 \%$ options). Other financial institutions $(65.8 \%)$ play a key role in this segment, however, the share of central counterparties does not reach the level of even $1 \%$. The US equities (46.8\%) and European equities (29.3\%) are the main markets for the use of these derivatives.

Thus, in the structure of the world market of derivatives, Interest rate and Foreign exchange contracts are leading. At the same time, future contracts are most often used on the exchanged market for trading in these instruments, and on the OTC market - outright forwards and forex swaps. By counterparty in trading, this derivative on the stock exchange is dominated by a central counterparty, while in the over-thecounter market their participation is very limited. Forwards, swaps and options are most often used in the commodity and equity-linked contracts markets. In the credit market of derivative instruments, the main buyers are central counterparties, but in the commodity market, their role is minimalized.

\section{Reform and prospects for the development of the derivatives market}

The financial crisis of 2008 necessitated the reform of the derivative financial instruments system. In the absence of strict control, they were exposed to significant speculative risks. This, in turn, negatively affected the entire financial system and the world economy. In November 2009 the G-20 finance ministers and central bank governors endorsed 20 recommendations to address information gaps described in the report "The Financial Crisis and Information Gaps" prepared by the Financial Stability Board (FSB) Secretariat and International Monetary Fund (IMF) staff (The Financial Crisis...). From the mentioned list, recommendations 13 provided «investigating the issue of monitoring and measuring cross-border, including foreign exchange derivative, exposures of non-financial, and financial, corporations with the intention of promoting standardized reporting guidance and the dissemination of data».

From the expert point of view, the main factor that needed to be addressed was the lack of data on crossborder exposures of non-financial corporations, in particular of larger corporations using foreign affiliates to raise finance, provide implicit guarantees, or engage in derivative transactions. Small and medium firms that were highly concentrated in exporting in some instances also acquired foreign exchange exposures through derivatives contracts booked in foreign markets.

To solve the identified problems, during 20102020 a number of measures were taken to reform the system of derivative financial instruments. As a result, significant progress has been made in many aspects of the reform, including:

- process improvement was provided to reduce reporting barriers and masking relief, wider use of the legal entity identifier in trade reporting, and streamlining reporting processes and trade repository operations; - the standards and criteria of the central clearing were improved, as a result, a significant proportion of OTC derivative transactions have been standardized; - complex margin requirements for non-centrally cleared derivatives were formed and systematized; 
- higher capital requirements for non-centrally cleared derivatives were established;

- comprehensive platform trading requirements were formed and applied.

According to the taken measures, a significant number of procedures for the use of derivatives were unified, most standards and criteria for control and monitoring were improved, and separate operations were centralized and unified according to market requirements (The Financial Crisis...).

Today, the most relevant processes that transform the derivatives market are the transition away from Libor, expected in 2021, and the implementation of Phases 5 and 6 of the Uncleared Margin Rules (UMR) over the next two years. Both have the potential to impact end-users at many levels by, among other things, changing their product mix to include more products linked to alternative reference rates to manage the former and more cleared products to manage the latter.

New challenges and opportunities that will have an impact on the global derivatives market in the nearest future will remain, on the one hand, COVID-19, and technological progress, on the other, including the creation of new technologies and derivatives. Response to COVID-19 impacts on the OTC derivatives markets, the efficacy of the OTC derivatives market reforms was tested during the pandemic and has so far held up, with no severe disruptions being reported in OTC derivatives markets, FMIs, or market participants across jurisdictions, notwithstanding the sharp increases in volatility and trade volumes in March 2020. After the initial spike, volumes have generally stabilized to preCOVID-19 levels (Afrina, Beg, Zayed, Hossain, Shahi, 2020). Accordingly, the derivatives market has responded effectively to new risks and adapted them through its own instruments.

Concerning the application of technological advances, in addition to the development of new tools, today's promising areas of market development are the formation of the segment of cryptoderivatives. The available information and technological resources can already fully operate with these tools. However, cryptocurrency markets today still have a controversial status in the world's financial system. Moreover, they are characterized by excessive volatility and cannot yet fully meet market requirements.

Thus, nowadays the derivatives market is gradually unifying and gaining controllability, especially in the OTC segment, despite the significant miscalculations in the management of the derivative system in the late 2000s. In such conditions, the role of clearing companies grows, conditions are created for clearer identification of market participants, management of margin, capital, trading platforms, etc. Promising directions for its further development today are the adaptation of the derivative system to the challenges associated with COVID-19, as well as to the opportunities arising from the spread of block chain and cryptocurrency technologies.

\section{Conclusions}

As a result of our research, we systematized information on the state of the derivatives market, conducted a study of its parameters, and substantiated the prospects for its further development. Accordingly, the following conclusions are noteworthy:

1. The global economy is exposed to many challenges and risks due to the high dynamism, political and economic instability. The sensitivity of the financial system to all kinds of shocks necessitates the widespread use of derivatives to reduce uncertainty and hedge risks. Given this, the global derivatives market today is 7.5 times the size of world GDP, and its indicators significantly affect global and local economic processes.

2. The current state of development of the derivatives market has a restrained positive trend. Considering the dominating OTC segment, it has been found that the availability of more flexible derivatives and less formal controls create an additional advantage for economic agents seeking to hedge their risks. This conclusion is confirmed by the positive reaction of the OTC market to the COVID-2019 crisis and the maintaining positive growth trend.

3. The main part of the derivatives market is formed by highly liquid instruments - Interest rate and Foreign exchange contracts. Their use is typical for both exchanged and OTC market. The key tools for securing derivatives are future contracts, outright forwards, and forex swaps. Commodity and equity-linked contracts most often operate forwards, swaps and options.

4. Considering the reform of derivative financial instruments launched after 2008, special attention is paid to counterparties that work with derivatives. In this context, we note the growing role of central counterparties in the market of exchanged future contracts, and in the market of Credit default swaps.

5. In line with the ongoing transformation, the OTC derivatives market is increasingly taking on the features of a unified and standardized system. On the one hand, this increases the level of its manageability, and on the other hand, reduces its attractiveness for speculative capital. Therefore, in current conditions using global risks, opportunities, and their adaptation to the risk management system is important for maintaining a high level of attractiveness of the derivatives market is. The risks related to the COVID-19 along with current scientific developments and the cryptocurrency market deserves special attention.

In view of the findings, the possibility of introducing derivative financial instruments in the block chain and 
cryptocurrency system is an important area of further research. Particular attention should be paid to the argumentation of the derivatives' potential, determining the degree of their possible market impact, and the development of clear sequences and algorithms for their implementation in the work of financial institutions.

\section{References:}

Afrina, T., Beg, T. H., Zayed, N. M., Hossain, M. S., \& Shahi, S. K. (2020). An Analysis of the Effects of Corona Virus (COVID-19) on International Financial Derivatives Market. Indian Journal of Finance and Banking, 4(2), 93-98. DOI: https://doi.org/10.46281/ijfb.v4i2.757

Bank for International Settlements (BIS) (2019). BIS Statistical Bulletin. Available at: https://www.bis.org/ statistics/bulletin1912.pdf (accessed 17 September 2021).

Greenberger, M. G. (2010, June). The Role of Derivatives in the Financial Crisis: Hearing before the Financial Crisis Inquiry Commission (111th Cong). Financial Crisis Inquiry Commission. Available at: https://fcic-static.law.stanford.edu/cdn_media/fcic-testimony/2010-0630-Greenberger.pdf (accessed 18 September 2021).

McPartland, K., \& Manohan, K. (2020). Derivatives Market. Structure 2020. Available at: https://www.fia.org/ sites/default/files/2020-03/Derivatives-Market-Structure-2020-PRINT.20-2012\%20(2).pdf (accessed 17 September 2021).

Sheludko, V. (2014). Suchasni tendentsii rozvytku svitovoho rynku deryvatyviv [Modern tendencies of development of the world market of derivatives]. Bulletin of Taras Shevchenko National University of Kyiv. Economics, $10,81-87$.

Shmuratko, Y. (2015). Tendentsii rozvytku svitovoho ta vitchyznianoho rynkiv pokhidnykh finansovykh instrumentiv [Trends of development of global and national derivatives market]. Hlobalni ta natsionalni problemy ekonomiky, 8, 1075-1079.

The Financial Crisis and Information Gaps Progress Report Action Plans and Timetables Prepared by the IMF Staff and the FSB Secretariat (2010). Available at: https://www.fsb.org/wp-content/uploads/r_100510.pdf (accessed 19 September 2021).

The World Bank (2021). World Development Indicators. DataBank. Available at: https://databank.worldbank.org/ source/world-development-indicators (accessed 19 September 2021).

Vo, D., Huynh, S., Vo, A., \& Ha, D. (2019). The Importance of the Financial Derivatives Markets to Economic Development in the World's Four Major Economies. Journal of Risk and Financial Management, $12(1), 35$. DOI: https://doi.org/10.3390/jrfm12010035 